\title{
Transcriptional Regulation of Epithelial to Mesenchymal Transition Related Genes by Lipopolysaccharide in Human Cervical Cancer Cell Line HeLa
}

\author{
Shaian Tavakolian, Hossein Goudarzi, Gita Eslami, Ebrahim Faghihloo*
}

\begin{abstract}
Objective: Cancer is one of the common diseases in the world, and cervical cancer is the fourth one. In this type of cancer, many risk factors, especially infectious diseases, such as human papilloma virus (HPV) and gram-negative bacteria can have important effects on the expression of epithelial to mesenchymal transition related genes like Snail, $E$-cadherin, and ZEB-1, responsible for connecting cell tissues. In this study, we have investigated the effect of Escherichia coli O111:B4 Lipopolysaccharide (LPS) on HPV positive cell line (HeLa), the expression level of the (Snail, E-cadherin, and $Z E B-1)$, HPV oncogenes $(E 6, E 7)$ and also microRNA-9, 192. Materials and Methods: HeLa cell line was treated with LPS to analyze Snail, E-cadherin, ZEB-1,E6, E7 and also microRNA-9, 192 expression by quantitative real-time PCR in 24, 48 and 72 hours. Results: Quantitative real-time PCR revealed a significant reduction in E-cadherin $m R N A$ level at $10 \mathrm{ug} / \mathrm{L}$ of LPS in three time-points and after 24 hours at $5 \mathrm{ug} / \mathrm{L}$ of LPS; however, ZEB-1 at $10 \mathrm{ug} / \mathrm{L}$ of LPS and Snail at 5, 10ug/L of LPS are up-regulated. E7 also illustrated a slight increase, but we did not find any relationship between $E 7$ and LPS treatment. Additionally, there are upward trends in microRNA-9, 192 levels. Conclusion: The result of this study, LPS is able to reduce E-cadherin expression, caused by increase in repressor E-cadherin protein expression and some microRNAs, probably. Since bacterial infection can be in cervical site, it is likely to be effective in reducing the E-cadherin expression in the EMT and enhance cancer process, therefore; removing these infections by using the appropriate antibiotics may result in slowing down this process, which requires more research.
\end{abstract}

Keywords: HPV- LPS- Snail- E-cadherin- ZEB-1

Asian Pac J Cancer Prev, 20 (8), 2455-2461

\section{Introduction}

Cancer is one of the most causes of death, and there are multiple types of cancer in the world. Among different types of this disease, cervical cancer causes more than 200,000 deaths, annually (Pisani et al., 2002). This cancer is the fourth common cancer in the word (Lai et al., 2019), and the diagnosis of more than 75,000 new cases of invasive cervical malignancy is estimated in the United States (Louie et al., 2002).

Many risk factors seem to be involved in the progression of cervical cancer, including radiation, environmental pollution, (Scheurer et al., 2014; Eslamizadeh et al., 2018) alcohol consumption, smoking (Kapeu et al., 2009), and even infectious diseases (Salimi et al., 2017; Faghihloo et al., 2014; Vaezjalali et al., 2013). Nowadays, it has been accepted that human papilloma virus (HPV) has a strong relationship with cervical cancer (Franco, 1995; Faghihloo et al., 2014; Mirzaei et al., 2018) HPV is a non-enveloped virus, and has double stranded DNA (Favre, 1995). E6 and $E 7$ are the HPV oncoproteins with significant roles in cervical cancer development, and with disrupting tumor suppression like P53, E6 is able to accelerate the progression of cancer (Thomas et al., 1999); in addition, binding $\mathrm{E} 7$ to $\mathrm{Rb}$ promotes the degradation of tumor suppressor protein proteasome (Syrjänen and Syrjänen, 1999).

Furthermore, many bacteria are able to live in vaginal site, especially gram- negative ones. When the balance of immune system and this flora destroyed, bacteria can replicate; therefore, bacteria tend to produce some inflmatory mediators, probably (Donders et al., 2014). One of the common agents in structure of flora, especially in gram-negative bacteria is cell wall, called Lipopolysaccharide (LPS) (Sharma et al., 2014) LPS can induce $N F-k B$ and $T L R-4$ expression, which call immune cells to inflmatory site.

Metastasis stage is a hardly curable disease in all kind of cancers, and cervical metastasis is no exception. In invasive cervical cancer, connecting adhesive proteins are reduced between cells; hence, tumor cells are able to spread in all parts of body, replicate, and create

Department of Microbiology, School of Medicine, Shahid Beheshti University of Medical Sciences, Tehran, Iran. *For Correspondence: faghihloo@gmail.com 
tumor cell (Granados López and López, 2014; Insinga et al., 2014) This process has been defined as epithelial to mesenchyme transition (EMT), related to the low expression of connecting inter cellular proteins (Kalluri and Neilson, 2003) E-cadherin is one of the important $E M T$ related protein families, which is involved in the adhesion between cells. Some other EMT related proteins like ZEB-1 and Snail may also regulate the expression of E-cadherin (Grooteclaes and Frisch, 2000), and reduce the expression of adhesive cell proteins; therefore, metastasis can occur (Vaure and Liu, 2014).

It is supposed that, the level of EMT related genes and HPV oncoproteins $(E 6, E 7)$ and some microRNAs such as mir-9, mir-192 expression can have an effect on cancer progression. Virtually, it has been reported, there is a strong relationship between cervical cancer and HPV; however, the effect of bacterial LPS on cervical cancer, and the relationship between $H P V$ and $L P S$ on EMT related genes expression in cervical cancer is not clear. In this study, human cervical cancer cell line (Hela) was treated with LPS, and the expression of EMT-related genes was evaluated.

\section{Materials and Methods}

\section{Cell culture and treatment}

HeLa cell line (cervical carcinoma), which is HPV positive, cultured in Dulbecco's Modified Eagle Medium (DMEM, gibco ) with $2 \mathrm{mM}$ / L-glutamine (Sigma-Aldrich, MO, USA), supplemented with $10 \%$ fetal bovine serum (Life Technologies, Camarillo, CA, USA), and 100 units/ $\mathrm{ml}$ penicillin/streptomycin (Invitrogen, Life Technologies, Camarillo, CA, USA). Cells were incubated in $37^{\circ} \mathrm{C}$ and 5\% $\mathrm{CO}_{2}$ ( IR.SBMU.MSP.REC.1396.879.).

\section{Lipopolysaccharide preparation}

Escherichia coli (E.coli) O111:B4 Lipopolysaccharide (LPS) was prepared from (Sigma-Aldrich, MO, USA). In order to make five different concentrations $(1,2,5,10$, and $20 \mathrm{ug} / \mathrm{l})$, LPS was dissolved in phosphate buffered saline (PBS).

\section{Proliferation assay}

Escherichia coli O111:B4 Lipopolysaccharide (LPS) was evaluated by MTT assay with using the 3-(4, 5-Dimethylthiazol-2-yl)-2, 5-diphenyltetrazolium bromide (MTT). Briefly, HeLa cell line was incubated in 96 well-plates with a condition of $37^{\circ} \mathrm{C}$ and $5 \% \mathrm{CO}_{2}$ until cells reach sufficient population. Medium containing LPS at concentrations of $0,1,2,5,10$ and $20 \mathrm{ug} / 1$ was added into 96-well plates. Then, $20-\mu \mathrm{l}$ MTT solution $(0.25 \mathrm{~g} /$ ml) was added in 24, 48 and 72 hours, and incubated for 4 hours in incubator with previous condition. DMSO was added, and the absorbance was measured at $570 \mathrm{~nm}$ and $625 \mathrm{~nm}$. HeLa cell line without treatment was employed as control.

\section{RNA extraction}

HeLa cell line was seeded in 12 well-plates. After filling the 80 percent of plate, HeLa cell line was treated with medium containing various concentrations of LPS (1 ug/1, $5 \mathrm{ug} / 1,10 \mathrm{ug} / \mathrm{l})$ in 24, 48 and 72 hours . To RNA extraction, RNX-plus solution (Cinnagen, Tehran, Iran) and chloroform were employed to discharge proteins. Then, RNA was precipitated with propanol, and washed with $70 \%$ alcohol. Finally, the RNA quality and quantity was evaluated at the wavelength of $260 \mathrm{~nm}$ by nanodrop spectrophotometry (Eppendrof, Humburg, Germany). The purity of RNA was also analyzed by running with $1 \%$ agarose gel electrophoresis.

\section{cDNA synthesis}

cDNA synthesis kit was purchased from BioFACT (Daejeon, South Korea). Cellular gene cDNA was synthesized by reverse transcriptase and random hexamers. We have added $10 \mu \mathrm{l}$ of RNA, $1 \mu \mathrm{l}$ of random hexamer and $9 \mu$ reverse transcriptase in a sterile micro centrifuge tube to make a $20 \mu \mathrm{l}$ final volume.

microRNAcDNAwas prepared by $10 \mu$ lofRNA, and $10 \mu \mathrm{l}$ of reverse transcriptase, and $0.5 \mu$ l of microRNA-9 primer TCCGAGGTATTCGCACTGGATACGACTCATAC-3'), and $0.5 \mu 1$ of microRNA-192 primer (5'-GTCGTATCCAGTGCAGGGTCCGAGGTATTC GCACTGGATACGACGGCTGT-3') to make cDNA, respectively.

All samples were incubated in $50^{\circ} \mathrm{C}$ for 40 minutes, and after that incubated in $95^{\circ} \mathrm{C}$ for 5 minutes. All cDNAs were diluted (2 times in sterile water), and as template for quantitative real-time PCR analysis.

\section{Quantitative real-time PCR}

The expression of cellular genes (Snail, E-cadherin, ZEB-1, and GAPDH) and microRNA (microRNAs -9,192) were analyzed by using the BIOFACT ${ }^{\mathrm{TM}} 2 \mathrm{X}$ real-time PCR master mix (for SYBR Green I; BIOFACT, South Korea); Furthermore, in this study, the expression of E6 and $E 7$ genes in HPV positive cell line (HeLa cell line) were evaluated.

SYBR master mix, $1 \mu$ of forward primer, $1 \mu \mathrm{l}$ of reverse primer, $2 \mu \mathrm{l}$ of $1 / 2$ diluted cDNA and $6 \mu$ lof sterile water were combined. To confirm our results, all samples were run in triplicate at the same time. The primers of all genes were documented in Table 1.

We have two temperature profiles for cellular and microRNA genes: $95^{\circ} \mathrm{C}$ for 10 minutes; 40 cycles of 95 ${ }^{\circ} \mathrm{C}$ for $30 \mathrm{Seconds}, 55^{\circ} \mathrm{C}$ for $30 \mathrm{Seconds}$, and $72^{\circ} \mathrm{C}$ for 30 Seconds for cellular genes, and $95^{\circ} \mathrm{C}$ for 10 minutes; 40 cycles of $95^{\circ} \mathrm{C}$ for $20 \mathrm{Seconds}, 60^{\circ} \mathrm{C}$ for $20 \mathrm{Seconds}$, and $72^{\circ} \mathrm{C}$ for 20 Seconds for microRNA. Melting curve program was between 60 and $95^{\circ} \mathrm{C}$.

The threshold cycle (ct) of all genes in treated cell line was compared with the ct of control cell line ,then all cellular and microRNA were normalized with housekeeping gene (GAPDH and $\mathrm{u} 6$ ), respectively, by the $2^{-\Delta \Delta \mathrm{ct}}$ method.

\section{Statistical analysis}

Graph-Pad Prism software was used to analyze the difference between groups, and ANOVA test shows the comparison between mRNA levels. We consider the $\mathrm{P}$-value less than $0.05(\mathrm{P}<0.05)$ as statistically significant 
for the differences.

\section{Results}

\section{Optimization of the LPS concentration}

The best LPS concentrations to measure the expression of cellular and microRNA are 1, 5 and $10 \mathrm{ug} / \mathrm{L}$ of LPS in 24, 48 and 72 hours. The data was not shown.

LPS down-regulates the expression of E-cadherin

After treating with LPS in 24, 48 and 72 hours, RNA was extracted by RNX-plus, and cDNA was synthesized. Quantitative real-time was employed to analyze EMT related genes. The E-cadherin has revealed a noticeable down-regulation in all times of 10ug/L of LPS and 24 hours after treating with $5 \mathrm{ug} / \mathrm{L}$ of LPS (Figure 1).

\section{LPS up-regulates the expression of Snail}

In our study, 5 and $10 \mathrm{ug} / \mathrm{L}$ of LPS can have a strong influence on expression of Snail. We have found in this period of time Snail has an up-ward trend expression, but 1ug/L of LPS ,Snail has not a meaningful increase (Figure 2).

\section{ZEB-1 is over expressed by treating LPS}

Analysis of another gene (ZEB-1) has demonstrated a meaningful increase in 48 and 72 hours after treating
Table 1. the Primer of Cellular Genes and microRNA, Evaluated with Real-Time PCR

\begin{tabular}{ll}
\hline Primer name & Sequence \\
\hline ZEB-1 (Forward) & 5'-GATGATGAATGCGAGTCAGATGC-3' \\
ZEB-1 (Reverse) & 5'-CTGGTCCTCTTCAGGTGCC-3' \\
Snail 1 (Forward) & 5'-CAGACCCACTCAGATGTCAA-3' \\
Snail 1 (Reverse) & 5'-CATAGTTAGTCACACCTCGT-3' \\
E7 (Forward) & CCGCTCGAGATGCATGGACCTAAGGCAAC \\
E7 (Reverse) & CGCGGATCCTTACTGCTGGGATGCACACC \\
E-cadherin & AGGGGTTAAGCACAACAGCA \\
(Forward) & \\
E-cadherin & GGTATTGGGGGCATCAGCAT \\
(Reverse) & \\
GAPDH (Forward) & ATGTTCGTCATGGGTGTGAA \\
GAPDH (Reverse) & GGTGCTAAGCAGTTGGTGGT \\
U6 (Forward) & 5'-GAGAAGATTAGCATGGCCCCT- 3' \\
U6 (Reverse) & 5'-ATATGGAACGCTTCACGAATTTGC-3' \\
miRNA -9-5P & 5'-CTTTGGTTATCTAGCTGTATGAGTCGT-3' \\
(Forward) & \\
Forward miRNA & 5'-CTGACCTATGAATTGACAGCCGT-3' \\
-192-5P (Forward) & \\
Universal Reverse & 5'-ATCCAGTGCAGGGTCCGA-3' \\
\hline
\end{tabular}

10ug/L of LPS in HeLa cell line. Generally, LPS induces an increase in ZEB-1 expression at 1 and $5 \mathrm{ug} / \mathrm{L}$ of LPS,

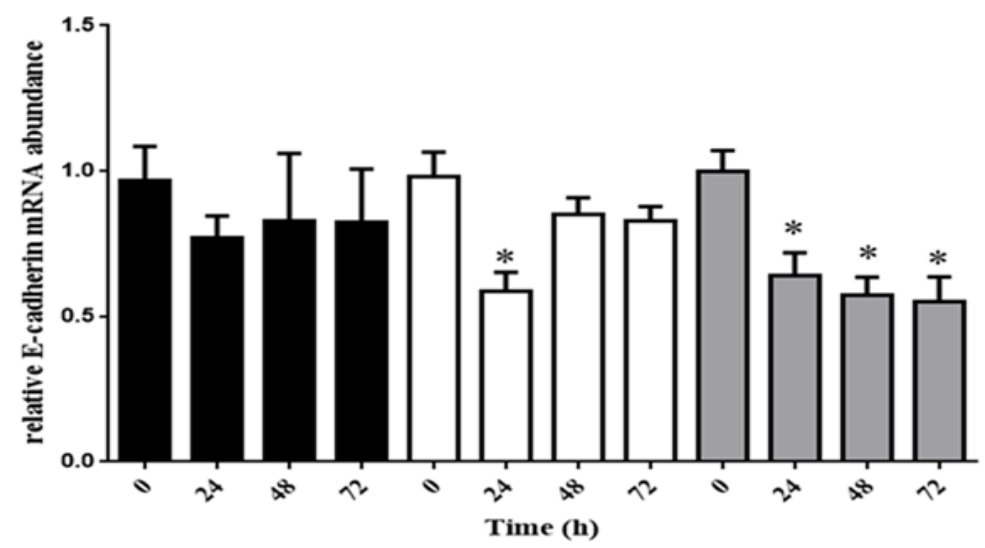

Figure 1. HeLa Cell Line was Treated with LPS by 1,5 and $10 \mathrm{mmol} / \mathrm{L}$, when the Cells Reached $80 \%$ Confluency. In all times of $10 \mathrm{mmol} / \mathrm{L}$ of LPS and 24 hours after treating with $5 \mathrm{mmol} / \mathrm{L}$ of LPS, E-cadherin expression have been raised.

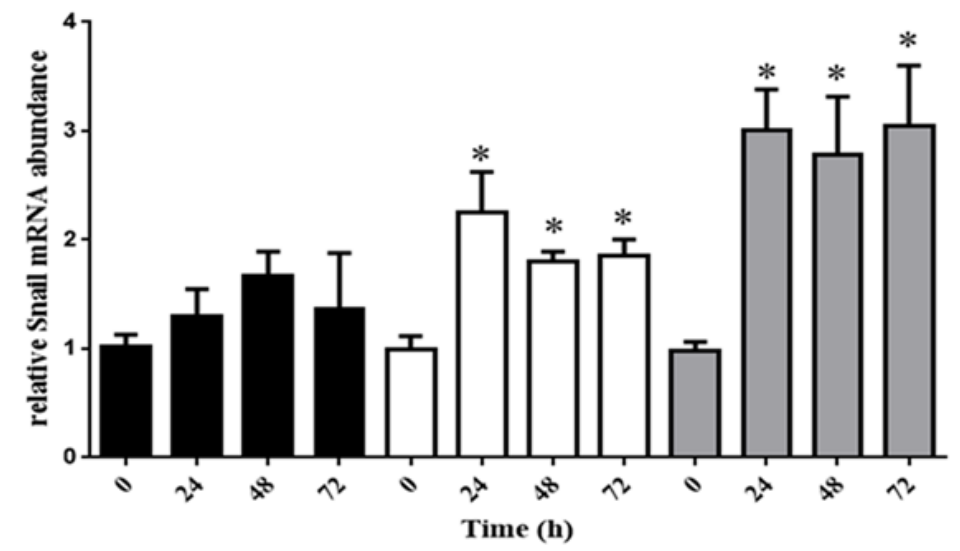

Figure 2. HeLa Cell Line have been Cultured with DMEM Containing LPS at Concentration of 1, 5 and $10 \mathrm{mmol} / \mathrm{L}$. Snail Expression was Revealed a Remarkable Growth in 5 and $10 \mathrm{mmol} / \mathrm{L}$ of LPS. 


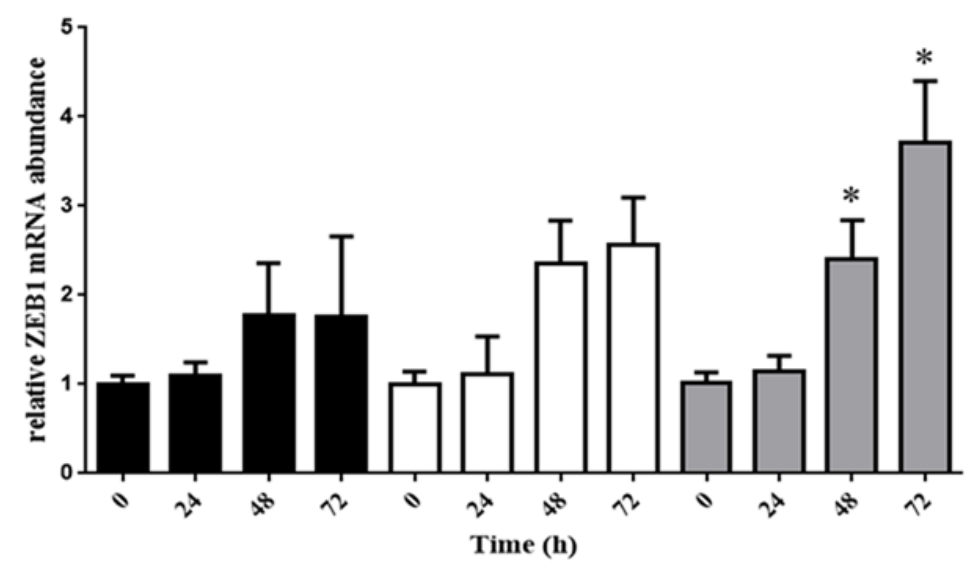

Figure 3. LPS is Able to Increase Expression of ZEB-1, in HeLa Cell Line, after 48 and 72 hours in $10 \mathrm{mmol} / \mathrm{L}$.

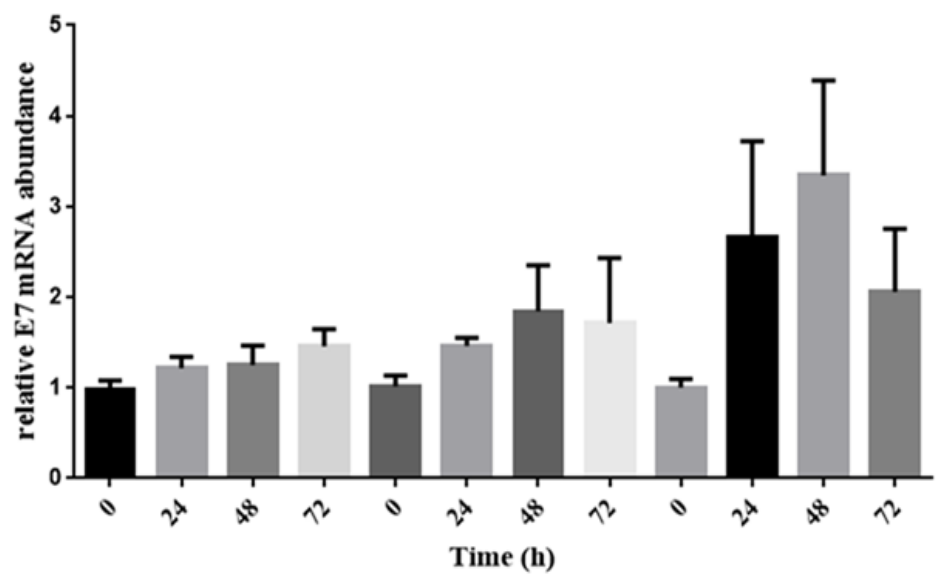

Figure 4. The Level of E7 HPV Expression after Treating HeLa Cell Line with LPS .The bar graph have demonstrated a meaningful increase in amount of $E 7 \mathrm{HPV}$ expression, however it is not meaningful relation.

but it was not meaningful, statistically (Figure 3).

\section{LPS increases E7 HPV expression}

LPS is able to increase the level of $E 7 H P V$ expression, but in our study, we have not found any meaningful relationship between LPS and the expression of $E 7 \mathrm{HPV}$ (Figure 4).

MicroRNA-9 and 192 expression is up-regulated by LPS We analyzed two microRNAs (microRNA-9 and 192) expression. There are an increase in amount of
microRNA-9 (almost 12 times) and 192 (almost 8 times) expression (Figure 5).

\section{Discussion}

Epigenetic changes may result in changes in gene expression. EMT related genes, such as Snail, ZEB-1 are important gene groups help cells in different organs to connect each other, especially Snail, E-cadherin, and ZEB-1. Down, or up-regulation of these genes can have some effects on cancer progression and invasive
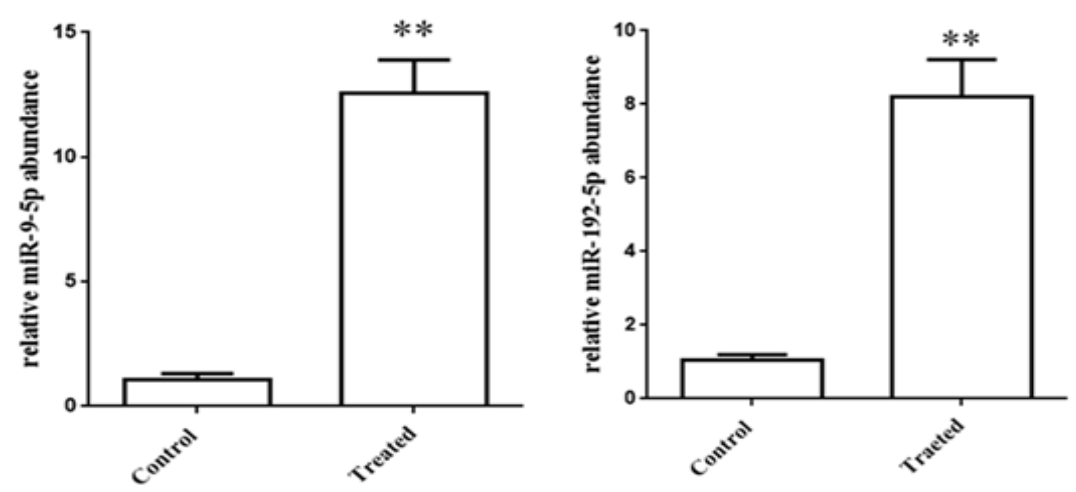

Figure 5. There are a Remarkable Increase in the amount of microRNA-9 and 192 Expressions after Treating LPS to HeLa Cell Line. 
metastasis (Adhya and Basu, 2010).

Cervical cancer is the second most important cancer in women, all around the world (Ferlay et al., 2012), and risk factors, ranging from pollution, radiation, smoking and consumption of alcohol to infectious diseases can affect the EMT related genes expression (Scheurer et al., 2014). We studied on the effect of gram- negative bacterial cell wall.

LPS, which is known endotoxin, is a vital structure in all kinds of bacteria, composed of lipid and polysaccharide. This molecule has a complex structure, which can be divided in 3 parts: outer hydrophilic O-antigenic polysaccharide side chain, a hydrophilic core polysaccharide and a hydrophilic lipid, and this hydrophilic lipid acts as an endotoxin (Kilár et al., 2013). We have purchased E.coli O111:B4 LPS to find what might be the relation between bacterial flora and $H P V$ is, and how EMT related genes expression changes.

Our result shown, $10 \mathrm{ug} / \mathrm{L}$ of LPS is able to decrease 1.5 times E-cadherin expression .Other studies have the same results for example, Porphyromonas gingivalis-LPS was examined in human gingival epithelial cells, and E-cadherin expression destruct epithelial barrier function (Abe-Yutori et al., 2017) LPS on some cells like macrophages can activate TNF and IL-6 secretion by Raw264.7 pathway, which induces a decrease in E-cadherin expression (Van den Bossche et al., 2015). Other studies have used some LPS antagonism, for example it has studied the effects of Shikonin, an antagonism of LPS, and observed that it can prevent down-regulation of E-cadherin from the effect of LPS in breast cancer cell line (Hong et al., 2015).

Another important EMT related genes is Snail, after treating HeLa cell line with LPS, considerable increase in amount of Snail is observed. Briefly, LPS at concentration of 5 and $10 \mathrm{ug} / \mathrm{l}$ is able to increase the expression of Snail, in HeLa cell line, almost duplicate and triplicate, respectively. This result is similar to some other studies, for example in study of Jing, when human hepatocellular carcinoma cell line (HCC) is treated with LPS. In this case in HCC, LPS is able to activate TLR-4 receptor, promoted $\mathrm{NF}-\kappa \mathrm{B}$ signaling, and Snail increases, subsequently (Jing et al., 2012), furthermore; activation of TLR-4 by LPS can also induce VEGF, Therefore; VEGF causes increase in Snail expression and metastasis progress (Zhu et al., 2016). The study has offered to use Curcumin as an antagonism of LPS. Curcumin can regulate the snail over-expression, induced by LPS (Huang et al., 2013).

We have supposed, LPS with effecting on Snail can lose E-cadherin expression. It seems, Snail is a repressor binding to the E-cadherin promoter, and leads to lose of E-cadherin expression (Cano et al., 2000; Takagi et al., 1998). Actually, in order to repress E-cadherin promoter, Snail requires histone deacetylase activity (Jiang et al., 2013) Peinado has suggested, trichostatin a can inhibit histone deacetylase activity, therefore ; snail is not able to reduce E-cadherin expression (Peinado et al., 2014).

In this study, we examined the $Z E B-1$ expression by treating HeLa cell line with LPS. 10ug/L of LPS is able to increase in $Z E B-1$ expression. It seems, $Z E B-1$ with the same mechanism of snail can inhibit the expression of E-cadherin (Comijn et al., 2001). We have supposed, LPS by increasing $Z E B-1$ level can down-regulate the E-cadherin expression. Recently, it has been suggested that Claudin-1, like LPS can up-regulate $Z E B-1$ expression, consequently E-cadherin is repressed (Singh et al., 2011).

HeLa is a HPV positive cell line, and E7 integrated in HeLa genome. Our result is demonstrated, LPS can cause a slight increase in amount of $E 7$ expression, but there is no meaningful correlate between $L P S$ and E7. Probably, E7 may repress the E-cadherin by DNA methyltransferase 1 (DNMT1) expression. Laurson et al., (2010) Caberg also has supposed, decrease in E-cadherin expression perhaps result from repressing RB by E7 (Caberg et al., 2008). One of other mechanisms has reported that $E 7$ may be over-express cdc6, which is one of key factors to reduce E-cadherin expression (Faghihloo et al., 2016). We suppose, LPS by over-expression of $E 7$, reduce E-cadherin. It has shown valproic acid has the same effect on E7, and E-cadherin down-regulate, subsequently. (Faghihloo et al., 2016)

MicroRNA is able to regulate EMT genes (Abba et al., 2016) Observations have shown, different microRNAs can mediate the expression of E-cadherin (Wong et al., 2014). Furthermore, in this study, LPS treatment was able to increase in amount of microRNA-9 and 192 expressions almost 12 and 8 times, respectively. The result of other studies confirm our experiment for example, Flavia Bazzoni has suggested, LPS activate TLR-4, therefore $\mathrm{NF}-\kappa \mathrm{B}$ signaling initiate, and microRNA-9 increase (Bazzoni et al., 2009). Wu et al., (2012) also found after treating LPS, microRNA-192 over-expressed. Probably, microRNA-9 is able to suppress E-cadherin (Zhou et al., 2017) $L P S$ over-expresses microRNA-9 and 192 , and these microRNAs can down-regulate E-cadherin expression, probably.

In conclusion, LPS is able to have effects on EMT related genes, such as E-cadherin, Snail and ZEB-1; therefore, gram-negative bacterial infectious diseases in cervix probably can have the same mechanism, and the cervical cancer progression can occur due to LPS in gram- negative bacteria in this site. To prevent cervical cancer progression in early stages, using appropriate antibiotics, is suggested.

\section{Acknowledgements}

The present article is financially supported by Research Department of the School of Medicine Shahid Beheshti University of Medical Sciences (grant No.12577).

\section{Ethical Considerations}

IR.SBMU.MSP.REC.1396.879.

\section{Conflict of Interest}

The authors declare no conflicts of interests.

\section{Authors' Contributions}

E.F., SH.T, assisted in the study design and performed the cell culture and molecular experiments. H.G., G.E performed the statistical Analyses. All authors read and approved the final version of the manuscript.

Asian Pacific Journal of Cancer Prevention, Vol 20 


\section{References}

Abba ML, Patil N, Leupold JH, Allgayer H (2016). MicroRNA regulation of epithelial to mesenchymal transition. J Clin Med, 14, pii: E8.

Abe-Yutori M, Chikazawa T, Shibasaki K, Murakami S (2017). Decreased expression of E-cadherin by Porphyromonas gingivalis-lipopolysaccharide attenuates epithelial barrier function. J Periodontal Res, 52, 42-50.

Adhya D, Basu A (2010). Epigenetic modulation of host: new insights into immune evasion by viruses. J Biosci, 35, 647-63.

Bazzoni F, Rossato M, Fabbri M, et al (2009). Induction and regulatory function of miR-9 in human monocytes and neutrophils exposed to proinflammatory signals. Proc Natl Acad Sci U S A, 106, 5282-7.

Caberg JH, Hubert PM, Begon DY, et al (2008). Silencing of E7 oncogene restores functional E-cadherin expression in human papillomavirus 16-transformed keratinocytes. Carcinogenesis, 29, 1441-7.

Cano A, Perez-Moreno MA, Rodrigo I, Locascio A, Blanco MJ (2000). The transcription factor Snail controls epithelialmesenchymal transitions by repressing E-cadherin expression. Nat Cell Biol, 2, 76-83.

Comijn J, Berx G, Vermassen P, et al (2001). The two-handed $\mathrm{E}$ box binding zinc finger protein SIP1 downregulates E-cadherin and induces invasion. Mol Cell, 7, 1267-78.

Donders GG, Zodzika J, Rezeberga D (2014). Treatment of bacterial vaginosis: what we have and what we miss. Exp Opin Pharmacother, 15, 645-57.

Eslamizadeh S, Heidari M, Agah S, et al (2018). The role of MicroRNA signature as diagnostic biomarkers in different clinical stages of colorectal cancer. Cell J, 20, 220-30.

Faghihloo E, Saremi MR, Mahabadi M, Akbari H, Saberfar E (2014). Prevalence and characteristics of Epstein-Barr virus-associated gastric cancer in Iran. Arch Iran Med, 17, $767-70$.

Faghihloo E, Saremi MR, Mahabadi M, Akbari H, Saberfar E (2014). Prevalence and characteristics of Epstein-Barr virusassociated gastric cancer in Iran. Arch Iran Med, 17, 767-70.

Faghihloo E, Sadeghizadeh M, Shahmahmoodi S, Mokhtari-Azad T (2016). Cdc6 expression is induced by HPV16 E6 and $E 7$ oncogenes and represses E-cadherin expression. Cancer Gene Ther, 2016, Nov 11.

Favre M (1975). Structural polypeptides of rabbit, bovine, and human papillomaviruses. J Virol, 15, 1239-47.

Ferlay J, Soerjomataram I, Ervik M, et al (2012). GLOBOCAN 2012 v1.0, Cancer Incidence and Mortality Worldwide: IARC CancerBase No. 11

Franco EL (1995). Cancer causes revisited:human papillomavirus and cervical neoplasia. J Natl Cancer Inst, 87, 779-80.

Granados López AJ, López JA (2014). Multistep model of cervical cancer: Participation of miRNAs and coding genes. Int J Mol Sci, 15, 15700-33.

Grooteclaes ML, Frisch SM (2000). Evidence for a function of $C t B P$ in epithelial gene regulation and anoikis. Oncogene, 19, 3823-8.

Hong D, Jang SY, Jang EH, et al (2015). Shikonin as an inhibitor of the LPS-induced epithelial-tomesenchymal transition in human breast cancer cells. Int J Mol Med, 36, 1601-6.

Huang T, Chen Z, Fang L (2013). Curcumin inhibits LPS-induced EMT related through down regulation of NF-кB-Snail signaling in breast cancer cells. Oncol Rep, 29, 117-24.

Insinga RP, Glass AG, Rush BB (2004). Diagnoses and outcomes in cervical cancer screening: a population-based study. $\mathrm{Am}$ J Obstet Gynecol, 191, 105-13.

Jiang GM, Wang HS, Zhang F, et al (2013). Histone deacetylase inhibitor induction of epithelial-mesenchymal transitions via up-regulation of Snail facilitates cancer progression. Biochim Biophys Acta, 1833, 663-71.

Jing YY, Han ZP, Sun K, et al (2012). Toll-like receptor 4 signaling promotes epithelial-mesenchymal transition in human hepatocellular carcinoma induced by lipopolysaccharide. BMC Med, 10, 98.

Kalluri R, Neilson EG (2003). Epithelial-mesenchymal transition and its implications for fibrosis. J Clin J Clin Invest, 112, 1776-84.

Kapeu AS, Luostarinen T, Jellum E, et al (2009). Is smoking an independent risk factor for invasive cervical cancer? A nested case-control study within Nordic Biobanks. Am J Epidemiol, 169, 480-8.

Kilár A, Dörnyei Á, Kocsis B (2013). Structural characterization of bacterial lipopolysaccharides with mass spectrometry and on- and off-line separation techniques. Mass Spectrom Rev, 32, 90-117.

Lai TO, Boon SS, Law PT, et al (2019). Oncogenicitiy Comparison of Human Papillomavirus Type 52 E6 Variants. J Gen Virol, 100, 484-96.

Laurson J, Khan S, Chung R, Cross K, Raj K (2010). Epigenetic repression of E-cadherin by human papillomavirus $16 \mathrm{E} 7$ protein. Carcinogenesis, 31, 918-26.

Louie KS, de Sanjose S, Mayaud P (2009). Epidemiology and prevention of human papillomavirus and cervical cancer in sub-Saharan Africa: A comprehensive review. Trop Med Int Health, 14, 1287-302.

Mirzaei H, Goudarzi H, Eslami G, Faghihloo E (2018). Role of viruses in gastrointestinal cancer. $J$ Cell Physiol, 233, 4000-14.

Peinado H, Ballestar E, Esteller M, Cano A (2004). Snail mediates E-Cadherin repression by the recruitment of the Sin3A/Histone deacetylase 1 (HDAC1)/HDAC2 complex. Mol Cell Biol, 24, 306-19.

Pisani P, Bray F, Parkin DM (2002). Estimates of the worldwide prevalence of cancer for 25 sites in the adult population. Int J Cancer, 97, 72-81.

Salimi V, Ramezani A, Mirzaei H, et al (2017). Evaluation of the expression level of 12/15 lipoxygenase and the related inflammatory factors (CCL5, CCL3) in respiratory syncytial virus infection in mice model. Microb Pathog, 109, 209-13.

Scheurer ME, Danysh HE, Follen M, Lupo PJ (2014). Association of traffic-related hazardous air pollutants and cervical dysplasia in an urban multiethnic population: a cross-sectional study. Environ Health, 13, 52

Sharma H, Tal R, Clark NA, Segars JH (2014). Microbiota and pelvic inflammatory disease. Semin Reprod Med, 32, 43-9.

Singh AB, Sharma A, Smith JJ, et al (2011). Claudin-1 up-regulates the repressor ZEB-1 to inhibit E-Cadherin expression in colon cancer cells. Gastroenterology, 141, 2140-53.

Syrjänen SM, Syrjänen KJ (1999). New concepts on the role of human papillomavirus in cell cycle regulation. Ann Med, 31, 175-87.

Takagi T, Moribe H, Kondoh H, Higashi Y (1998). A zinc finger and homeodomain transcription factor, is required for skeleton patterning in multiple lineages Development, 125, 21-31.

Thomas M, Pim D, Banks L (1999).The role of the E6-p53 interaction in the molecular pathogenesis of HPV. Oncogene, 18, 7690-700.

Vaezjalali M, Rashidpour S, Rezaee H, et al (2013). Hepatitis B viral DNA among HBs antigen negative healthy blood donors. Hepat Mon, 13, e6590.

Van den Bossche J, Laoui D, Naessens T, et al (2015). E-cadherin expression in macrophages dampens their inflammatory 
responsiveness in vitro, but does not modulate M2-regulated pathologies in vivo. Sci Rep, 5, 12599.

Vaure C, Liu Y (2014). A comparative review of toll-like receptor 4 expression and functionality in different animal species. Front Immunol, 10, 316.

Wong TS, Gao W, Chan JY (2014). Interactions between E-Cadherin and MicroRNA Deregulation in Head and Neck Cancers: The Potential Interplay. Biomed Res Int, 2014, 126038.

Wu TH, Pan CY, Lin MC, et al (2012). In vivo screening of zebrafish microRNA responses to bacterial infection and their possible roles in regulating immune response genes after lipopolysaccharide stimulation. Fish Physiol Biochem, 38, 1299-1310.

Zhou B, Xu H, Xia M, et al (2017). Overexpressed miR-9 promotes tumor metastasis via targeting E-cadherin in serous ovarian cancer. Front Med, 11, 214-22.

Zhu G, Huang Q, Huang Y, et al (2016). Lipopolysaccharide increases the release of VEGF-C that enhances cell motility and promotes lymphangiogenesis and lymphatic metastasis through the TLR4- NF- $\mathrm{BB} / \mathrm{JNK}$ pathways in colorectal cancer. Oncotarget, 7, 73711-24.

\section{cc) (i) (8)}

This work is licensed under a Creative Commons AttributionNon Commercial 4.0 International License. 